\title{
Study on Introduction of Leisure Sports into Physical Education in Universities
}

\author{
Qingshan $\operatorname{Sun}^{1}$ \\ ${ }^{1}$ Department of Physical Education, Qingdao University of Science and Technology, Qingdao, China \\ Correspondence: Qingshan Sun, Department of Physical Education, Qingdao University of Science and \\ Technology, Qingdao 260042, China. E-mail: sunqs099@163.com
}

Received: May 29, 2013 Accepted: June 6, 2013 Online Published: August 1, 2013

doi:10.5539/ass.v9n10p71 URL: http://dx.doi.org/10.5539/ass.v9n10p71

\begin{abstract}
With implementation of the outline of the nationwide body-building plan and formulation of sports health curriculum in universities, university sports education has been gradually transited from the single function of strengthening students' physical quality to the direction of diversification development of body-building, sports entertainment, social intercourse, lifelong sports and so on. Leisure sports have become a new tide in sports development in a global scope with its characteristics of sociality, lifelong and living and are the necessary direction of human social development and civilization progress. Formation of university students' habit of "leisure sports" during the period of university learning is an important means to carry out lifelong sports and participation of university students in leisure sports plays an important role in cultivating university students' consciousness of lifelong engagement in sports. Therefore, introduction of leisure sports into sports education in universities seems quite necessary.
\end{abstract}

Keywords: university, physical education, leisure sports

\section{Introduction}

Leisure sports are one of the leisure life styles. Leisure sports help to strengthen the physical quality, improve both the physical and psychological health, cultivate good morality, promote the overall development of students and enable them to be dedicated into their job, learning and creativity activities with plentiful energy. Leisure sports education not only teaches students how to spend their leisure time, but more importantly, educates students how to use in a valuable way their leisure time to enhance their life process, improve their life quality and really become a person with sound mind and intelligence, perfect personality and, love in work, learning and life. As a kind of positive and healthy leisure life style, leisure sports are able to effectively improve health, practice the physique, enjoy both the mind and body, alleviate pressure brought by social life and become an important means in promoting personal perfection. Leisure sports of university students are a kind of leisure activity in which university students independently choose the style of sports activities in their leisure time for leisure and recreation and to meet with personal development. Leisure sports in universities in an important means to realize lifelong sports and development of leisure sports in universities complies with the need of university sports to cultivate a person with overall development.

\section{The Concept and Characteristics of Leisure Sports}

\subsection{The Concept of Leisure Sports}

According to Liu Yimin, recreational sports (leisure sports) are not simply a kind of new sports means, but are defined on the activity time of the subjects participating in sports activities. It is a kind of body activity means in which people take advantage of their leisure time for the aim of body building, entertainment, and recreation, etc. (Liu, 1996).

Yu Tao defines leisure sports from the perspective of philosophy as a kind of modern sports behavior mode in which people positively and actively pursue and share pleasure in sports activities with a self-conscious feeling of self-improvement and self-enrichment on the basis of the material wealth and spiritual wealth created in the industrial society and in the post-industrial society (Yu, 2001).

Xue Haihong et al quote definition on leisure sports by Lin Zhichao in "Leisure and Leisure Sports". That is, recreational sports (namely, leisure sports) are a kind of mass sports activity conducted in the leisure time of 
work and study, and, as an important component of the leisure life, can enable the participant to attain the purpose of strengthening the physical quality, promoting health, recovering physical strength, regulating the psychology, edifying the taste, stimulating the enthusiasm in life, cultivating lofty quality, satisfying spiritual pursuit and sharing pleasure in life in an atmosphere imbued with joy and harmony by means of participating in all kinds of physical activities (Xue et al., 2001).

Yu Kehong holds the view that, leisure sports are exercised in the leisure time, a kind of meaning modern life mode which produces the optimal psychological experience by the means of certain physical activity. In this kind of sports, the participants are not subject to any strict regulation of activity and have the freedom to positively pursue internal experience and to make both the personal spirit and body get relaxed (Yu).

From the above research results, it can be found that, what people focus on is a descriptive analysis of leisure sports. In this article, the author holds the view that leisure sports concentrate more on joy and relax of spirit and, as a matter of fact, focus more on psychological experience, but weaken the organizational mode of the activity and the degree of profession. Thus, it can be seen that compared with sports education and competitive sports, leisure sports have more obvious flavor in life and are a kind of sports in life.

Thus, in this paper, "leisure sports" are defined as follows: Leisure sports are a kind of healthy and scientific body movement mode which people voluntarily participate in and independently choose and which is based on the major means of body participation and is aimed to alleviate pressure, entertain both the body and mind, adjust the emotion and keep in good health. Leisure sports education is also a kind of social practical activity with integration of competition, manifestation, entertainment and education which seeks for healthy development of personal body and mind. It can not only promote healthy life of an individual and satisfy the needs of an individual, but can also enrich cultural life of students, improve the cultural standard of students, enhance their life quality and enable the life quality of students to get effective improvement.

\subsection{Characteristics of Leisure Sports in Universities}

\subsubsection{Autonomy of University Students' Activities}

Leisure sports independently selected by university students is a kind of behavioral process without any compulsive feeling of pressure that is completely chosen by university students themselves independently. This kind of sports is a sports behavior that has obvious consciousness characteristics and tendency of students. The sports activity participated by university students during their leisure time can go without constraint by any organization or group and students can totally select a sports activity item by themselves according to their own personality, interest and capacity. In order for university students to participate in a sports activity, they have to possess complete independence.

\subsubsection{Diversification of Activity Forms and Content}

The activity forms of leisure sports can be appreciative activity, relatively stable activity and body movement activity, while selection of content can be chess playing, card playing, fishing, ball playing, ice and snow skating, qigong, Chinese martial arts, folk dance, standard dancing, Latin dance, mountain climbing and orientation movement in accordance with the favor of an individual, the surrounding environment and the condition of the individual.

\subsubsection{Enhancing University Students' Moral Quality and Civilization Consciousness}

Quite a lot of items in leisure sports have the competitive characteristics, so university students have the opportunity to exercise their willpower and reinforce their consciousness of struggling in a fair, justified and open competitive environment. In the meantime, leisure sports in universities are able to effectively adjust the emotional condition of students, enhance the basic activity and capacity of adapting to the environment and cultivate university students' perfect psychological quality. Therefore, they are the most effective means to promote university students' overall physical and psychological development and rapidly enhance university students' moral quality and civilization consciousness.

\subsubsection{Comprehensiveness of Activity Utility}

Leisure sports have the functions of enhancing people's consciousness of civilization and moral quality, effectively adjusting people's emotional condition, enhancing people's basic activity and capacity of adapting to the environment and cultivating a perfect psychological quality. Thus, they are the most effective means to promote the overall development of both body and mind of people.

\subsubsection{Entertainment of Activity Content}

Leisure sports are not only aimed for physical health, but more importantly, to enjoy happiness through 
movement. Leisure sports can not only bring sensory happiness, but can also create spiritual happiness. "When a person is a person in its complete sense, he must be playing. And he can only be a complete person when he is playing." Those engaged in leisure sports can accept it just like a game, as leisure sports do not require one to concentrate his efforts on skills, but only needs one to experience happiness in the process of participation, which stimulates the interest of the participants.

\subsection{Value of Universities in Implementing Leisure Sports Education}

The period of university life is an important period in lifelong development and is a stage towards maturity. At this stage, the cognition in oneself, others and the society tends to be stable and the world outlook of a person is also formed. Implementation of leisure sports at this stage not only has a direct effect on students' physical and psychological health, but also has an influence on their healthy life quality after they step into the society in the future.

\subsubsection{Promoting Fulfillment of "Becoming Man" and Realizing Self-value}

Leisure is a kind of condition of the life, a long-lasting but important stage. "When a person is a person in its complete sense, he must be playing. And he can only be a complete person when he is playing." People pursue happiness in leisure and also search for meaning of life. Meanwhile, their also make full use of leisure to sense life, experience the value, significance, ideal, humanity, personality, good and evil, beauty and ugliness of being a person and comprehend the value and significance of life. Leisure sports are an experience of both body and spirit, an integration of man and the environment and a feeling and realization of sociality of man, life significance, life value and self-fulfillment of man. It promotes integration and maturity of man and the nature and the society.

\subsubsection{Forming Good Life Style and Enhancing the Life Quality}

Statistically, each academic year, one third of university students' time is "free time", as a result of which the problem of "stirring up troubles" become prominent. Selection of sports as the leisure mode of university students can strengthen the physical quality of university students and also effectively improve and promote the physical health condition of students. In the meantime, in entertainment of interest and under the influence of latent rules of sports activities, people are able to form a good life style, change the previous inflexible and tedious pace of life and change unhealthy life style.

\subsubsection{Purpose and Ultimate Direction of Human Leisure}

The purpose and ultimate direction of human leisure is to pursue relax and rest in terms of soul, body and spirit, while sports leisure can exactly make one obtain healthy spirit, and imbued with happiness and joy. However, the most valuable and significant effect is that people are likely to appreciate the spiritual and cultural atmosphere of leisure sports. The spirit of leisure sports is to experience aesthetics, morality, creation and surpassing in freedom, and it is significant and non-utilitarian. What it brings to us is a kind of particular cultural deposits which supports our spirit, protects our spiritual home and makes our soul find a place to stay and to depend on.

\section{Necessity of Introducing Leisure Sports into University Sports Education in Shandong Province}

\subsection{Leisure Sports Help to Promote Development of Quality-oriented Education and Fulfillment of Lifelong Sports}

Leisure sports enhance students' physical health and edify students' moral sentiment by the means of sports activity mode. The feature of freedom of leisure sports enables students to creatively learn to guide themselves how to spend the leisure time in a healthy way in the process of participation. Its feature of collectivity cultivates students' concept of mutual assistance and strengthens their collective concept. All these features happen to be the same with the thought of quality oriented education. The lifelong sports thought originates from the theory of lifelong education and is put forward to adapt to the social development and to meet with people's higher demand on health. It breaks through the framework of traditional school sports education. Sports education is not only aimed to impart sports knowledge and skills, but more importantly, to le students know about the importance of physical health. And the key to cultivate the consciousness of lifelong sports is to stimulate students' interest.

\subsection{Adapt to the Need of a Well-off Society Development}

With development of the well-off society, the era of leisure is approaching and, as a kind of natural leisure mode imbued with vigor of youth, a variety of light-hearted and joyful sports leisure and entertainment activities gradually become an important content for modern people to adapt to the modern life and to share the life. Leisure sports education in universities is supposed to keep pace with the development of the society. Therefore, 
implementation of leisure sports education among university students is an objective requirement of social development. Furthermore, leisure sports education is also part of the socialization education of university students. The current university leisure sports education does not conform with the fact that the country is gradually stepping into a leisure society. This also indicates the urgency of carrying out leisure sports education in higher institutions of learning. As an important group of the society and as the fresh troops in building a well-off society, university students possess relatively strong acceptance capacity and high cultural quality, and it is more suitable to carry out leisure sports education among the university students.

\subsection{Help to Enhance University Students'Social Adaptation Capacity and Innovative Capacity}

In the process of engaging in collective leisure sports activities, university students often play different roles and all kinds of rules are just like "simulation" of the various social roles in the real life. They gradually experience, perceive and comprehend the social position and functions of all kinds of roles in the activities as well as corresponding rights, obligations and responsibilities of all roles. This is of great significance to cultivate students' innovative consciousness, innovative quality and innovative capacity.

\subsection{Compensating for the Need of Deficiency in the Traditional Sports Education}

The traditional sports education does not totally follow the objective rule of epistemology and has failed to fully reflect the education thought of "human orientation". The traditional sports education has laid excessive emphasis on the theory and skills of competitive s ports, while it has ignored the theory and skills of leisure sports. Leisure sports are an important component of "lifelong sports". Sports education is not only aimed to impart sports skills, but is also supposed to put the leisure theory and leisure skills of man on a due position as the content of sports education. In this way, sports education is comprehensive and perfect and can reflect the thought of "lifelong sports".

\subsection{Help to Cultivate University Students' View of Life Values}

Leisure sports are experience of both body and mind, integration of man and the environment and are feeling and reflection of man in the society and life value and self-realization. In leisure sports activities, contact between man and the nature casts the personality of perseverance, openness, generosity, broadness of mind and breadth of mind. Communication between men makes one sincere, friendly and harmonious and promotes the rational progress of man. University students in the contemporary society suffer from pressure from both school performance and employment, which gives rise to tension, exhaustion and anxiety. At the time when they experience smoothness through leisure sports, they also leave behind the separation between learning, working and leisure and are able to more actively pursue and search for the optimal soul experience.

\section{Influencing Factors in Introduction of Leisure Sports into University Sports Education in Shandong Province}

1) Sports Culture Atmosphere in University Campus. University campus is a large group that has great influencing power. Both the culture of campus leisure sports and the condition of the group participating have an influence on the development of university students' leisure sports. The university is supposed to concentrate on building up an atmosphere of leisure sports, enlarge students' vision of field in this regard and, to a certain extent, direct and promote healthy development of leisure sports.

2) The social leisure life style has a direct effect on the activity content and activity patterns of university students and has a significant guidance meaning in the sports teaching objective, teaching content, teaching progress, teaching method and evaluation standard, etc.

3) The type, condition and scale of sports athletic field facilities in universities have an impact upon university students' participation in leisure sports activities. It is indicated by the survey data that, a large majority of students hold the view that, the current sports athletic field facilities in universities are unable to meet with the demand on leisure sports activities.

4) The organization mode of leisure sports is also an important factor in influencing implementation of leisure sports. A rational organization mode does not only have an effect on formation of a sound leisure sports management mechanism, but also has an effect on the enthusiasm and initiative of university students in participation in leisure sports.

5) The attitude of university managerial personnel towards leisure sports and their leisure values of keeping pace with the times determine the objective of physical education. On the base that the subject strongly recognizes the leisure value of sports, the orientation in selecting the leisure value of sports should be regarded as the guiding thought in establishing the teaching objective. The managerial personnel have to abandon the traditional 
prejudice of "emphasizing intellectual education and neglecting physical education" and have to stand on a height of harmony to survey physical education teaching.

\section{Conclusions and Suggestions}

\subsection{Strengthening Publicity of Leisure Sports and Strengthening University Students' Consciousness in Leisure Sports}

It is necessary to launch sports scientific special lectures, sports salon and sports comments to convey information about leisure sports fashion to students, impart physical fitness and health care knowledge, broaden the vision of students, encourage and guide students to participate in a variety of leisure sports activities so as to stimulate the consciousness of students to actively participate in sports activities, enable students to regard acceptance of sports education as a kind of internal need for self-development, promote university students to form a positive and forward sports life style and, furthermore, dedicate themselves positively into healthy, civilized and scientific leisure sports activities.

\subsection{Deepening Sports Curriculum Reform and Cultivating the Habit of Lifelong Sports Practice}

The existing university physical education curriculum is no longer to the advantage of further development of leisure sports, so it is a must to reform it. Firstly, we have to establish the teaching guidance thought of "human orientation", "health first" and "lifelong sports", pay attention to development of the personality of students and set up correct values on sports. Then, it is necessary to enrich content of sports teaching and make teaching materials in sports entertained. According to modern educational thought and scientific sports method, principle and human body development rule, we may make reasonable modification, processing, refinement and sublimation on some sports items to make them become sports teaching materials that meet with the diversified demand of university students on sports and make use of the process to conduct leisure sports education on students. Finally, the teaching methods are to be diversified and focus on the subjective effect and cultivation of personality of students. It is also necessary to reform the absolute evaluation in the past that merely concentrates on the result and to make a comprehensive evaluation on students' movement skill, learning attitude, will expression and range of advancement.

\subsection{Concentrating on Cultivation of Leisure Sports Teachers}

Physical education teachers are the critical factors that determine whether leisure sports education in universities can be carried out successfully. The knowledge level, personality quality and conduct of physical education teachers are of critically importance to acceptance of sports knowledge and skills by university students, formation of the outlook on sports and cultivation of the comprehensive quality. Therefore, it is necessary to take measures to strengthen construction of the teacher team. On one hand, it is necessary to take a positive attitude to bring in professional talents graduating from the major of leisure sports education and to enrich the teacher team with these talents. On the other hand, it is necessary to provide regular training on in-service teachers, strengthen external communication and create conditions to enable the teachers to be engaged in advanced studies so as to enhance their theory and teaching level in leisure sports.

\subsection{Strengthening Management of Leisure Sports}

With the extensive development of leisure sports activities in universities and colleges, the demand of university students becomes higher and universities and colleges are supposed to take effective measures to provide positive guidance for university students to participate in all kinds of leisure activities. Meanwhile, they also ought to pay attention to cultivation of student backbones in sports and ask them to organize sports activities at the level of class, grade and the whole university to form a situation of co-management and enable all the students to participate in leisure sports activities. As for cultivation of student backbones in sports, the physical education teachers should often show care and provide guidance for them to consolidate the training on basic knowledge and basic skills in leisure sports, continuously improve their business quality and service capacity and make efforts to play their role as the backbone in leisure sports activities so as to ensure successful implementation of leisure sports activities.

\subsection{Strengthening Construction of Sports Venue Facilities}

The administrative department for education and university leaders ought to come to full realization of the importance of consolidating construction of facilities in sports venue, try every means to increase capital investment in equipment and facilities in sports venue, continuously enlarge the sports activity area and add sports equipment and facilities so as to satisfy the demand of the vast majority of university students on leisure sports activities. In the meantime, they need to strengthen management of facilities in sports venue, make the facilities, to the greatest extent, play their effect and functions by means of extending the opening duration of 
sports venue, enhancing the consciousness of service and appropriate compensated use, and promote overall implementation of leisure sports in universities.

\section{References}

Chen, H. (2004). Sport and leisure service management. Journal of Physical Education, 23(5), 25-26.

Chen, Y. Z. (2007). Developmental Tendency of Leisure Sport in China. Journal of Shanghai University of Sport, 31(1), 13-14.

Hu, X. M. (2004). Theory and Practice of Sports Leisure. Beijing: Higher Education Press.

Hu, X. M., \& Yu, C. G. (2004). Theory and practice of sports and leisure. Beijing: Higher Education Press.

Li, B., \& Xu, B. L. (2002). Analysis on Status Quo of College Students' Sport Leisure in Chinese General Universities and Colleges. Journal of Shanghai Physical Education Institute, 26(1), 25-27.

Li, X. D., \& Peng, G. (2001). Discussion on Leisure Sport in China. Journal of Wuhan Institute of Physical Education, 35(5), 125-126.

Liu, Y. M. (n. d.). Leisure Sports - A Civilized Healthy and Scientific Life-Style at Leisure. Journal of Tianjin University of Sport, (11), 57-62.

Lu, Y. Z. (2007). Discussion on sports culture in China. Journal of Beijing University of Sport, 33(1), 23-24.

Ministry of Education. (2002). Physical Education Curriculum Guiding Outline for Common Institutes of Higher Learning in China.

Xi, Y. B., Gao, S., \& Yang, B. (2004). Discussion on Leisure and Leisure Sports. China Sport Science and Technology, 40(1), 51-54.

Xue et al. (2001). Leisure and Leisure Sports. Journal of Xi'an Physical Education, (4), 22.

Yu, T. (2001). Recreational Sport? Or Leisure Sport? Critical Review of Concept and Definition of Leisure Sport. Tianjin University of Sport, (3), 32-35.

\section{Copyrights}

Copyright for this article is retained by the author(s), with first publication rights granted to the journal.

This is an open-access article distributed under the terms and conditions of the Creative Commons Attribution license (http://creativecommons.org/licenses/by/3.0/). 